\title{
Thyroid function and metabolic syndrome in the population-based LifeLines cohort study
}

Bruce H. R. Wolffenbuttel ${ }^{1 *}$, Hanneke J. C. M. Wouters ${ }^{1}$, Sandra N. Slagter ${ }^{1}$, Robert P. van Waateringe', Anneke C. Muller Kobold ${ }^{2}$, Jana V. van Vliet-Ostaptchouk' ${ }^{1}$ Thera P. Links ${ }^{1}$ and Melanie M. van der Klauw ${ }^{1}$

\begin{abstract}
Background: The metabolic syndrome (MetS) is a combination of unfavourable health factors which includes abdominal obesity, dyslipidaemia, elevated blood pressure and impaired fasting glucose. Earlier studies have reported a relationship between thyroid function and some MetS components or suggested that serum free thyroxine (FT4) or free triiodothyronine (FT3) levels within the normal range were independently associated with insulin resistance. We assessed how thyroid function relates to MetS prevalence in a large population-based study.

Methods: Data of 26,719 people of western European descent, aged 18-80 years from the Dutch LifeLines Cohort study, all with normal thyroid stimulating hormone (TSH), FT4 and FT3 levels (electrochemiluminescent immunoassay, Roche Modular E170 Analyzer), were available. MetS was defined with the revised National Cholesterol Education Programs Adults Treatment Panel III (NCEP ATP III) criteria. We calculated prevalence of all MetS components according to TSH, FT4 and FT3 quartiles.

Results: At similar TSH levels and age (mean 45 yrs), men had significantly higher levels of FT4, FT3, blood pressure (BP), heart rate, total and LDL-cholesterol, triglycerides (TG), and creatinine, but lower HDL-cholesterol compared to women (all $p<0.001$ ). In total, $11.8 \%$ of women and $20.7 \%$ of men had MetS. In men, lower FT4 levels were associated with higher prevalence of MetS and all MetS components. In women, lower FT4 quartile was only associated with a higher prevalence of elevated TG, waist circumference, and MetS. However, when corrected for confounding factors like age, BMI, current smoking and alcohol consumption, a significant relationship was found between FT3 and three MetS components in men, and all five components in women. Moreover, the highest quartiles of FT3 and the FT3FT4 ratio predicted a $49 \%$ and $67 \%$ higher prevalence of MetS in men, and a 62 and 80\% higher prevalence in women.

Conclusions: When corrected for possible confounding factors, higher plasma levels of FT3 are associated with several components of the MetS. Only in men, lower FT4 is related to MetS. In the highest FT3 and FT3FT4 quartiles, there is a 50-80\% increased risk of having MetS compared to the lowest quartile. Further studies are needed to assess the possible causality of this relationship.
\end{abstract}

Keywords: Metabolic syndrome, Thyroid, Triiodothyronine, Epidemiology

\footnotetext{
* Correspondence: bwo@umcg.nl

'Department of Endocrinology, University of Groningen, University Medical

Center Groningen, HPC AA31, P.O. Box 30001, 9700 RB Groningen, The

Netherlands

Full list of author information is available at the end of the article
} International License (http://creativecommons.org/licenses/by/4.0/), which permits unrestricted use, distribution, and reproduction in any medium, provided you give appropriate credit to the original author(s) and the source, provide a link to the Creative Commons license, and indicate if changes were made. The Creative Commons Public Domain Dedication waiver (http://creativecommons.org/publicdomain/zero/1.0/) applies to the data made available in this article, unless otherwise stated. 


\section{Background}

The metabolic syndrome (MetS) is a clustering of medical conditions that reflects overnutrition, sedentary lifestyles, and resultant adiposity. Metabolic abnormalities such as abdominal obesity, hyperglycaemia, hypertension and dyslipidaemia often are present together, suggesting that they are not independent of one another and that they may share underlying causes and mechanisms [1]. Having MetS places a subject at a substantially increased risk to develop serious diseases like type 2 diabetes (T2D) and cardiovascular disease (CVD) [2].

In an earlier paper we described results from the population-based PREVEND study, and reported that low normal free thyroxine (FT4) levels were significantly related to a higher prevalence of all five MetS components in a group of almost 2300 people from the general population [3]. From this, we concluded that subjects with thyroid function in the low normal range already are at increased cardiovascular risk.

In recent years, there have been confusing results on the relationship between thyroid hormone levels within the normal range and cardiovascular risk factors and MetS. Several papers have described a relationship between thyroid hormone parameters and components of MetS [3-7]. However, some authors have reported an association between thyroid stimulating hormone (TSH) levels and metabolic risk factors, whereas others have observed that high normal free triiodothyronine (FT3) levels, and the FT3FT4-ratio were related to MetS. One of the largest study until now [4] evaluated 44,196 individuals (of whom 25,147 men), and reported that FT4 in men was significantly associated with blood pressure (BP), HDL-cholesterol (HDL-C), fasting blood glucose (FBG), and triglycerides (TG), and in women was associated with BP, HDL-C, FBG, waist circumference (WC). The authors however did not see an association with MetS, when adjusted for age. They did not adjust for smoking or alcohol, two important factors which influence the prevalence of MetS components, like low HDL$\mathrm{C}$, elevated triglycerides (TG), and -in women- increased WC [8]. Another study from Korea evaluated data from 13,496 middle-aged individuals, and found a relationship between higher $\mathrm{T} 3$ and T3/T4 and an unfavourable metabolic profile [6]. And a very recent paper reported in over 132,000 subjects that higher FT3/FT4 ratio was associated with increased risk of metabolic syndrome parameters and insulin resistance, adjusted for age, body mass index, smoking status and menopausal status (in women) [7].

For the current study, we used data of 26,719 participants from the population-based LifeLines Cohort Study to address the discrepancies in the literature. We aimed to investigate the relationship between thyroid hormone parameters and components of the MetS in this large sample of euthyroid subjects in the general population. As differences in MetS prevalence and thyroid hormone parameters have been demonstrated between men and women, we analysed these relationship separately for both sexes.

\section{Methods \\ Subjects}

For this cross-sectional study, we obtained data from subjects participating in the LifeLines Cohort Study. LifeLines is a multi-disciplinary prospective population-based cohort study examining in a unique three-generation design the health and health-related behaviours of persons living in the North of The Netherlands. It started in 2007, and employs a broad range of investigative procedures in assessing the biomedical, socio-demographic, behavioural, physical and psychological factors which contribute to the health and disease of the general population, with a special focus on multi-morbidity and complex genetics. The methodology has been described previously $[9,10]$. All participants provided written informed consent before entering the study. The study protocol was approved by the medical ethical review committee of the University Medical Center Groningen. For the present study, we included subjects with an age between 18 and 80 years, who were of Western European descent, in whom thyroid hormone parameters were measured, and found to be within the normal range. We excluded participants who were treated because of a thyroid disorder, or who were current users of drugs known to influence thyroid hormone parameters, like lithium, amiodarone, and corticosteroids. Also, participants with a CRP level $>10 \mathrm{mg} / \mathrm{L}$ were excluded, because inflammation may disturb the activity of the deiodinase enzymes and alter thyroid hormone levels.

\section{Clinical examination}

Subjects completed a self-administered questionnaire on medical history, past and current diseases, use of medication and health behaviour at home. Medication use was verified by a certified research assistant, and scored by ATC code. The number of different medications used by a participant was considered as a proxy for multimorbidity [11]. Participants were defined as never smoker, current smoker or former smoker. Alcohol intake was calculated as the average number of units of alcohol based on the response to specific questions regarding intake frequency. Individuals who reported that they had not consumed alcohol during the previous month were considered non-drinkers.

$\mathrm{BP}$ and anthropometric measurements were obtained using a standardized protocol $[9,10]$. BP was measured every minute during a period of $10 \mathrm{~min}$ with an automated DINAMAP Monitor (GE Healthcare, Freiburg, Germany). The average of the final three readings was 
recorded for systolic and diastolic BP. Height, weight, and waist and hip circumference were measured with the participant in light clothing and without shoes [8].

\section{Biochemical measurements}

Blood samples were collected between 8 and 10 a.m. after an overnight fast, directly into tubes containing heparin, and centrifuged. Total cholesterol (TC) and HDL-cholesterol (HDL-C) were measured with an enzymatic colorimetric method, triglycerides (TG) with UV colorometry, and LDL-cholesterol (LDL-C) using an enzymatic method (Roche Modular P chemistry analyser, Roche, Basel, Switzerland). HbA1c was measured with a turbidimetric inhibition immunoassay (Cobas Integra 800 CTS analyser, Roche Diagnostics Nederland BV, Almere, the Netherlands). Fasting blood glucose was measured using a hexokinase method. Levels of thyroid stimulating hormone (TSH), as well as free thyroxine (FT4) and free triiodothyronine (FT3) were assayed by electrochemiluminescent immunoassay (Roche Modular E170, Roche, Switzerland) [12]. Normal values for TSH are 0.4-4.5 mU/l, FT4 are 11$20 \mathrm{pmol} / \mathrm{L}$, for FT3 4.4-6.7 pmol/l. The general Dutch population is iodine sufficient. Tests to measure anti-thyroid peroxidase antibody levels were not performed.

\section{Calculations, definitions and statistical analysis}

Body mass index (BMI) was calculated as weight $(\mathrm{kg}) /$ height $\left(\mathrm{m}^{2}\right)$, and categorized as normal weight $\left(<25 \mathrm{~kg} / \mathrm{m}^{2}\right)$, overweight $\left(25-30 \mathrm{~kg} / \mathrm{m}^{2}\right)$ and obesity $\left(\geq 30 \mathrm{~kg} / \mathrm{m}^{2}\right)$. Diagnosis of type 2 diabetes was based either on self-report (known diabetes), or on the finding of a fasting blood glucose $\geq 7.0 \mathrm{mmol} / \mathrm{l}$ at LifeLines' screening (newly-diagnosed diabetes) [13]. Diagnosis of MetS was established if a subject satisfied at least three out of five criteria according to the modified guidelines of the National Cholesterol Education Programs Adults Treatment Panel III (NCEP ATPIII criteria) $[1,8]$. Relevant parameters were calculated according to FT4 and FT3 quartiles. As it is known that women and men differ regarding cardiovascular parameters, as well as MetS and thyroid hormone parameters, all calculations were made for both sexes separately.

Analyses were carried out with PASW Statistics (Version 24, IBM, Armonk, NY, USA). Data are presented as mean $\pm \mathrm{SD}$, or median and interquartile range when not normally distributed. Means were compared between groups with analysis of variance. In case of non-normal distribution, medians were compared with the nonparametric Kruskal-Wallis test. Chi-square test was used to analyse categorical variables. Both smoking and alcohol alter various components of the MetS [8]. Multiple linear regression models were therefore created to assess the associations of thyroid hormone parameters with the components of the MetS, with and without correction for factors known to influence either thyroid hormone parameters and MetS components: age, BMI, current smoking, and alcohol consumption. We subsequently used logistic regression analysis to estimate the odds ratios (ORs) and 95\% confidence intervals (CI) for quartiles of thyroid hormone parameters to predict the presence of MetS, again adjusted for age, BMI, as well as smoking and alcohol consumption. To allow adjustment for multiple comparisons, a $P$-value $<0.001$ was considered statistically significant.

\section{Results}

The characteristics of the participants are given for men and women separately in Table 1 . At similar TSH levels and age (mean $45 \mathrm{yrs}$ ), men had significantly higher levels of FT4, FT3, BP, heart rate, total and LDL-C, TG, and creatinine, but lower HDL-C compared to women (all $p<0.001$ ). In total, $11.8 \%$ of women and $20.7 \%$ of men had MetS.

In men, lower FT4 levels were associated with lower levels of FT3 and higher TSH levels, higher levels of BMI, WC, waist-to-hip ratio, BP, FBG, total and LDL-C and TG levels, but lower HDL-C. In the lowest FT4 quartile, there were also fewer current smokers. In contrast, lower FT3 quartiles were only associated with lower FT4, higher TSH, and higher age, and also with higher levels of TC, HDL-C and LDL-C, and with a lower percentage of current smokers. As a consequence, lower FT4 levels were associated with higher prevalence of all MetS components. The lowest FT4 quartile (Additional file 1: Table S1) was associated with the highest prevalence of elevated BP (60\%), elevated FBG (22.7\%), WC (33.4\%) and TG (30.2\%), low HDL-cholesterol (26.5\%), and MetS (27.7\%). In contrast, higher FT3 levels were associated only with low HDL-C.

In women, the lowest FT4 quartile was associated with lower FT3 and higher TSH, higher BMI and waist circumference, but not with age, or with differences in blood pressure or cholesterol levels, while triglyceride levels were slightly higher. As a consequence, low FT4 levels (Additional file 2: Table 2) were only associated with elevated TG (11.2\%), WC (47.4\%), and MetS (13.8\%). In contrast, higher FT3 levels were associated only with low HDL-C, and with a higher percentage of participants with $\geq 3$ MetS components.

It became apparent that age, BMI and current smoking were confounders in all analyses: higher age was associated with lower FT3, and the lower FT4 and FT3 quartiles contained fewer current smokers. Also, age, BMI, smoking and alcohol consumption are known to influence several MetS components. Therefore, we performed four models within linear regression analyses, in which model 4 corrects for all these confounders. The 
Table 1 Baseline characteristics of the participants

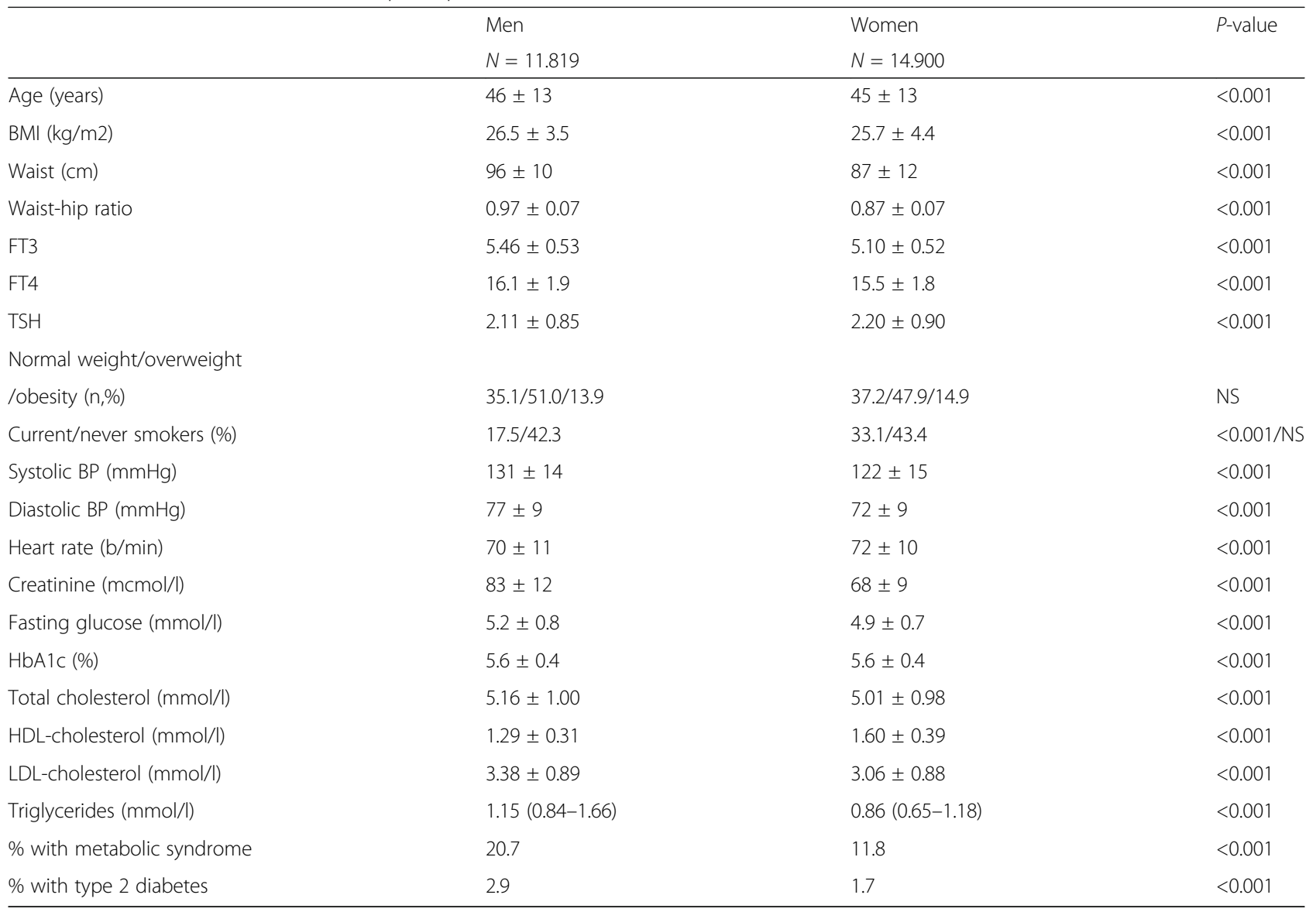

results of these analyses are depicted in Tables 2 and 3, and show some differences between men and women. In men, only the association between FT4 and TG remained significant after correcting for all confounders, while FT3 correlated with 3 of 5 MetS components (BP, HDL-C, WC). In women, FT3 was associated with all MetS components after correction for the confounders. In both men and women, the FT3FT4-ratio was associated 4 of the 5 components of MetS, but not with FBG.

Finally, Tables 4 and 5 depicts the results of the logistic regression analyses, in which we have correlated the thyroid parameters (divided in quartiles again) with the presence of MetS. In both men and women, higher levels of FT3 and the FT3FT4-ratio, adjusted for age, BMI, current smoking and alcohol consumption, were associated with a higher risk MetS, while FT4 was associated with higher risk of MetS in men only. Both for men and women, we observed a 1.67-1.80 higher OR for the highest FT3FT4-ratio quartile compared to the lowest quartile to predict the presence of MetS.

\section{Discussion}

In this large population-based study in subjects with thyroid hormone levels in the normal range, we have shown that higher levels of FT3 and the FT3FT4 ratio and lower levels of FT4 (in men only) are associated with components of MetS, when corrected for important confounders like age, BMI, current smoking and alcohol consumption. A significant relationship was found for FT3 and three MetS components in men, and all five components in women. Moreover, the highest quartiles of FT3 and the FT3FT4 ratio predicted a $49 \%$ and $67 \%$ higher prevalence of MetS in men, and a 62 and 80\% higher prevalence in women.

From our uncorrected analyses, FT4 levels appeared the most strongly related to MetS. However, it has been known that both age and BMI can influence thyroid hormone parameters and MetS. In the current study, we observed a gradual decrease of plasma FT3 levels with increasing age, while TSH and FT4 levels did not change significantly. Furthermore, it is known that FT4 levels are lower and TSH levels are higher in obese individuals compared to those with normal weight. This was the reason we included both parameters as confounders in our linear regression models. In addition, both smoking and alcohol consumption have a profound effect on some MetS components. Smoking lowers HDL-C levels, and is associated with increased WC, as we have 
Table 2 Associations of thyroid function with components of the metabolic syndrome in men

\begin{tabular}{|c|c|c|c|c|c|c|c|c|c|}
\hline & & FT4 & & FT3 & & TSH & & FT3FT4 & \\
\hline & Model & $\beta$ & $P$ & $\beta$ & $P$ & $\beta$ & $P$ & $\beta$ & $P$ \\
\hline SBP & 1 & -0.048 & $<0.001$ & 0.008 & 0.385 & 0.009 & 0.330 & 0.049 & $<0.001$ \\
\hline & 2 & -0.013 & 0.147 & 0.096 & $<0.001$ & 0.003 & 0.705 & 0.074 & $<0.001$ \\
\hline & 3 & -0.016 & 0.084 & 0.093 & $<0.001$ & 0.003 & 0.741 & 0.075 & $<0.001$ \\
\hline & 4 & 0.015 & 0.098 & 0.081 & $<0.001$ & 0.005 & 0.576 & 0.040 & $<0.001$ \\
\hline DBP & 1 & -0.048 & $<0.001$ & -0.047 & $<0.001$ & -0.017 & 0.066 & 0.009 & 0.304 \\
\hline & 2 & -0.005 & 0.584 & 0.054 & $<0.001$ & -0.024 & 0.007 & 0.039 & $<0.001$ \\
\hline & 3 & -0.006 & 0.486 & 0.052 & $<0.001$ & -0.027 & 0.002 & 0.039 & $<0.001$ \\
\hline & 4 & 0.020 & 0.023 & 0.041 & $<0.001$ & -0.026 & 0.003 & 0.009 & 0.312 \\
\hline HDL-C & 1 & 0.044 & $<0.001$ & -0.097 & $<0.001$ & -0.016 & 0.086 & -0.112 & $<0.001$ \\
\hline & 2 & 0.060 & $<0.001$ & -0.072 & $<0.001$ & -0.018 & 0.048 & -0.103 & $<0.001$ \\
\hline & 3 & 0.065 & $<0.001$ & -0.063 & $<0.001$ & -0.032 & $<0.001$ & -0.100 & $<0.001$ \\
\hline & 4 & 0.023 & 0.008 & -0.045 & $<0.001$ & -0.035 & $<0.001$ & -0.051 & $<0.001$ \\
\hline TG & 1 & -0.084 & $<0.001$ & 0.011 & 0.246 & 0.057 & $<0.001$ & 0.083 & $<0.001$ \\
\hline & 2 & -0.074 & $<0.001$ & 0.040 & $<0.001$ & 0.076 & $<0.001$ & 0.092 & $<0.001$ \\
\hline & 3 & -0.081 & $<0.001$ & 0.027 & 0.005 & 0.068 & $<0.001$ & 0.090 & $<0.001$ \\
\hline & 4 & -0.040 & $<0.001$ & 0.010 & 0.286 & 0.070 & $<0.001$ & 0.041 & $<0.001$ \\
\hline FBG & 1 & -0.074 & $<0.001$ & -0.040 & $<0.001$ & -0.003 & 0.710 & 0.038 & $<0.001$ \\
\hline & 2 & -0.042 & $<0.001$ & 0.037 & $<0.001$ & -0.009 & 0.333 & 0.062 & $<0.001$ \\
\hline & 3 & -0.043 & $<0.001$ & 0.036 & $<0.001$ & -0.008 & 0.353 & 0.062 & $<0.001$ \\
\hline & 4 & -0.014 & 0.112 & 0.024 & 0.010 & -0.007 & 0.456 & 0.028 & 0.001 \\
\hline Waist & 1 & -0.143 & $<0.001$ & -0.018 & 0.051 & -0.015 & 0.106 & 0.119 & $<0.001$ \\
\hline & 2 & -0.105 & $<0.001$ & 0.079 & $<0.001$ & -0.021 & 0.016 & 0.148 & $<0.001$ \\
\hline & 3 & -0.106 & $<0.001$ & 0.079 & $<0.001$ & -0.021 & 0.017 & 0.148 & $<0.001$ \\
\hline & 4 & -0.002 & 0.657 & 0.036 & $<0.001$ & -0.015 & 0.001 & 0.0125 & $<0.001$ \\
\hline
\end{tabular}

Values of $\beta$ are standardized regression coefficients

Regression for triglycerides was performed after logarithmic transformation. Significant associations are shown in bold

Model 1: crude

Model 2: after adjustment for age

Model 3: after adjustment for age, current smoking, alcohol consumption

Model 4: after adjustment for age, BMI, current smoking, alcohol consumption

demonstrated earlier within the LifeLines population [8]. Alcohol consumption may increase HDL-C levels, but also levels of $\mathrm{BP}[8,14,15]$. As our initial data analyses revealed that there were fewer smokers and users of alcohol in the lowest FT4 and FT3 quartiles, both in men and in women, we have corrected in our regression models for these factors as well. And only with these important adjustments, we were able to demonstrate that FT3 levels and the FT3FT4 ratio were significantly associated with MetS components, and having MetS.

Several papers have described the relationship between thyroid hormone parameters and components of MetS. In 2007, our group has demonstrated in the population-based PREVEND study the association between levels of FT4 (within the normal reference range) and plasma lipids; these findings were in accordance with the earlier observed association between (sub)clinical hypothyroidism and hyperlipidaemia [3]. Low normal FT4 levels proved to be significantly associated with MetS (four of five components) and increased insulin resistance. From our data, we concluded that this suggested an increased risk of cardiovascular events in subjects with low normal thyroid function [3]. Several additional papers, as summarized in Table 6, have been published the last decade which have assessed the relationship between thyroid hormone levels and cardiovascular risk factors, including the MetS. These studies have been performed in populations with different ethnic background. As can be seen in Table 6, there are significant differences between these studies, not only related to study setting and population, but also related to the results. One of the striking differences is that several papers have not separated between women and men, as it is known (which 
Table 3 Associations of thyroid function with components of the metabolic syndrome in women

\begin{tabular}{|c|c|c|c|c|c|c|c|c|c|}
\hline & & FT4 & & FT3 & & TSH & & FT3FT4 & \\
\hline & Model & $\beta$ & P & $\beta$ & $P$ & $\beta$ & $P$ & $\beta$ & $P$ \\
\hline SBP & 1 & 0.034 & $<0.001$ & 0.040 & $<0.001$ & 0.033 & $<0.001$ & 0.006 & 0.455 \\
\hline & 2 & 0.027 & $<0.001$ & 0.131 & $<0.001$ & 0.025 & 0.001 & 0.081 & $<0.001$ \\
\hline & 3 & 0.028 & $<0.001$ & 0.137 & $<0.001$ & 0.023 & 0.002 & 0.083 & $<0.001$ \\
\hline & 4 & 0.054 & $<0.001$ & 0.130 & $<0.001$ & 0.018 & 0.015 & 0.054 & $<0.001$ \\
\hline DBP & 1 & -0.003 & 0.754 & 0.015 & 0.06 & 0.007 & 0.426 & 0.017 & 0.044 \\
\hline & 2 & -0.007 & 0.400 & 0.064 & $<0.001$ & 0.002 & 0.823 & 0.058 & $<0.001$ \\
\hline & 3 & -0.006 & 0.461 & 0.068 & $<0.001$ & 0.000 & 0.962 & 0.059 & $<0.001$ \\
\hline & 4 & 0.014 & 0.078 & 0.063 & $<0.001$ & -0.004 & 0.658 & 0.037 & $<0.001$ \\
\hline HDL-C & 1 & 0.016 & 0.046 & -0.112 & $<0.001$ & 0.020 & 0.016 & -0.106 & $<0.001$ \\
\hline & 2 & 0.013 & 0.107 & -0.079 & $<0.001$ & 0.016 & 0.047 & -0.078 & $<0.001$ \\
\hline & 3 & 0.023 & 0.005 & -0.062 & $<0.001$ & 0.001 & 0.877 & -0.071 & $<0.001$ \\
\hline & 4 & -0.016 & 0.034 & -0.052 & $<0.001$ & 0.009 & 0.240 & -0.027 & $<0.001$ \\
\hline TG & 1 & -0.068 & $<0.001$ & 0.046 & $<0.001$ & 0.078 & $<0.001$ & 0.105 & $<0.001$ \\
\hline & 2 & -0.073 & $<0.001$ & 0.101 & $<0.001$ & 0.073 & $<0.001$ & 0.154 & $<0.001$ \\
\hline & 3 & -0.083 & $<0.001$ & 0.086 & $<0.001$ & 0.087 & $<0.001$ & 0.150 & $<0.001$ \\
\hline & 4 & -0.051 & $<0.001$ & 0.078 & $<0.001$ & 0.080 & $<0.001$ & 0.113 & $<0.001$ \\
\hline FBG & 1 & 0.000 & 0.964 & -0.011 & 0.161 & 0.036 & $<0.001$ & -0.003 & 0.731 \\
\hline & 2 & -0.007 & 0.405 & 0.059 & $<0.001$ & 0.029 & $<0.001$ & 0.057 & $<0.001$ \\
\hline & 3 & -0.007 & 0.405 & 0.059 & $<0.001$ & 0.029 & $<0.001$ & 0.056 & $<0.001$ \\
\hline & 4 & 0.025 & 0.001 & 0.051 & $<0.001$ & 0.023 & 0.002 & 0.020 & 0.011 \\
\hline Waist & 1 & -0.091 & $<0.001$ & -0.011 & 0.175 & 0.018 & 0.032 & 0.081 & $<0.001$ \\
\hline & 2 & -0.096 & $<0.001$ & 0.048 & $<0.001$ & 0.012 & 0.137 & 0.134 & $<0.001$ \\
\hline & 3 & -0.097 & $<0.001$ & 0.047 & $<0.001$ & 0.014 & 0.084 & 0.133 & $<0.001$ \\
\hline & 4 & -0.004 & 0.380 & 0.024 & $<0.001$ & -0.005 & 0.284 & 0.024 & $<0.001$ \\
\hline
\end{tabular}

Values of $\beta$ are standardized regression coefficients

Regression for triglycerides was performed after logarithmic transformation. Significant associations are shown in bold

Model 1: crude

Model 2: after adjustment for age

Model 3: after adjustment for age, current smoking, alcohol consumption

Model 4: after adjustment for age, BMI, current smoking, alcohol consumption

is also apparent from the current paper) that the prevalence of the individual MetS components differs considerably between women and men [16-19]. For instance, we have recently demonstrated that increased waist circumference is a common features of MetS among women while men have often an elevated blood pressure [20]. Moreover, FT4 and FT3 levels differ between men and women as well. Therefore, simply adjusting for sex may obscure possible differences between sexes. In addition, no study has reported data on smoking and alcohol consumption, or corrected for these important confounders. Interestingly, our data indicate a dysbalance of smoking and alcohol consumption in the different FT4 and FT3 quartiles, which causes a warning regarding the proper interpretation of earlier studies. With the exception of recent studies by Kim et al. [4], Park et al. [5] and by Kim et al. [6, 21], earlier studies have incorporated a limited number of participants.
There are a number of possible explanations for the relationship between FT3 and the different MetS components, c.q. insulin resistance. One may be that a small increase of T3 may directly influence insulin sensitivity. Recent data have supported this with the notion that overproduction of thyroid hormones may have a negative effect on peripheral insulin action [22]. Indeed, it has been shown that in obese individuals, who more frequently are insulin-resistant, FT4 levels are lower, and TSH and FT3 levels are higher. This has been postulated to be the consequence of an excess of nutrition, especially when consuming a diet high in fat. Obesity may directly influence tissue type 2 deiodinase activity -which converts T4 into T3- in order to compensate for this. It has also been argued that in the brain T3 may have a stimulatory effect on food intake behaviour, which can be considered a compensation for the increase of 
Table 4 Risk of having metabolic syndrome according to quartiles of thyroid hormone parameters, in men

\begin{tabular}{|c|c|c|c|c|c|c|}
\hline & Quartile & MetS/Total, n (\%) & model 1 & model 2 & model 3 & model 4 \\
\hline \multirow[t]{4}{*}{ TSH } & 1 & 578/2923 (19.8) & 1 & 1 & 1 & 1 \\
\hline & 2 & 595/2975 (20.0) & $1.014(0.893-1.153)$ & $1.015(0.892-1.155)$ & $1.030(0.904-1.174)$ & $1.000(0.861-1.161)$ \\
\hline & 3 & $618(2946$ (21.0) & $1.077(0.948-1.223)$ & $1.072(0.943-1.219)$ & $1.116(0.980-1.271)$ & $1.101(0.949-1.276)$ \\
\hline & 4 & 650/2975 (21.8) & $1.134(1.000-1.286)$ & $1.110(0.977-1.261)$ & $1.155(1.015-1.314)$ & $1.214(1.047-1.407)$ \\
\hline \multirow[t]{4}{*}{ FT4 } & 1 & 796/2877 (27.7) & 1 & 1 & 1 & 1 \\
\hline & 2 & 635/3000 (21.2) & $0.702(0.623-0.791) \#$ & $0.717(0.635-0.809) \#$ & $0.704(0.623-0.796) \#$ & $0.816(0.709-0.939) \#$ \\
\hline & 3 & 532/3014 (17.7) & $0.560(0.495-0.635) \#$ & $0.596(0.525-0.675) \#$ & $0.579(0.509-0.657) \#$ & $0.733(0.634-0.848) \#$ \\
\hline & 4 & 478/2928 (16.3) & $0.510(0.449-0.579) \#$ & $0.567(0.498-0.646) \#$ & $0.545(0.478-0.622) \#$ & $0.722(0.621-0.839) \#$ \\
\hline \multirow[t]{4}{*}{ FT3 } & 1 & $516 / 2655$ (19.4) & 1 & 1 & 1 & 1 \\
\hline & 2 & 652/3300 (19.8) & $1.021(0.897-1.161)$ & $1.192(1.045-1.360)$ & $1.172(1.026-1.339)$ \# & $1.174(1.010-1.366)$ \\
\hline & 3 & 695/3185 (21.8) & $1.157(1.018-1.315)$ & 1.487 (1.302-1.699) \# & 1.458 (1.275-1.668) \# & $1.360(1.167-1.586) \#$ \\
\hline & 4 & $578 / 2679$ (21.6) & $1.140(0.998-1.303)$ & 1.652 (1.434-1.904) \# & $1.577(1.366-1.821) \#$ & 1.491 (1.266-1.756) \# \\
\hline \multirow[t]{4}{*}{ FT3FT4 } & 1 & 457/2945 (15.5) & 1 & 1 & 1 & 1 \\
\hline & 2 & 528/2958 (17.8) & $1.183(1.031-1.357)$ & $1.241(1.080-1.426)$ & $1.220(1.060-1.405) \#$ & $1.234(1.054-1.445)$ \\
\hline & 3 & $667 / 2960$ (22.5) & $1.584(1.388-1.807) \#$ & 1.753 (1.533-2.005) \# & 1.731 (1.512-1.983) \# & 1.537 (1.318-1.791) \# \\
\hline & 4 & 789/2956 (26.7) & $1.982(1.743-2.255)$ \# & 2.263 (1.984-2.582) \# & $2.267(1.984-2.590) \#$ & $1.674(1.438-1.948)$ \# \\
\hline
\end{tabular}

Model 1: crude; model 2: adjusted for age; model 3: adjusted for age, current smoking and alcohol consumption

model 4: adjusted for age, BMI, current smoking and alcohol consumption

OR and $95 \% \mathrm{Cl}$ for metabolic syndrome were calculated using logistic regression models

Significant associations $(P<0.001)$ are shown in bold

Table 5 Risk of having metabolic syndrome according to quartiles of thyroid hormone parameters, in women

\begin{tabular}{|c|c|c|c|c|c|c|}
\hline & Quartile & MetS/Total, n (\%) & model 1 & model 2 & model 3 & model 4 \\
\hline \multirow[t]{4}{*}{ TSH } & 1 & 388/3726 (10.4) & 1 & 1 & 1 & 1 \\
\hline & 2 & $428 / 3710$ (11.5) & $1.122(0.970-1.298)$ & 1.149 (0.989-1.334) & $1.192(1.025-1.386)$ & $1.162(0.984-1.372)$ \\
\hline & 3 & 451/3729 (12.1) & $1.184(1.025-1.367)$ & $1.165(1.005-1.351)$ & 1.219 (1.049-1.417) & $1.046(0.885-1.236)$ \\
\hline & 4 & 493/3735 (13.2) & 1.308 (1.136-1.507) \# & $1.212(1.053-1.061)$ & $1.288(1.110-1.494)$ & $1.167(0.990-1.375)$ \\
\hline \multirow[t]{4}{*}{$\mathrm{FT} 4$} & 1 & 523/3784 (13.8) & 1 & 1 & 1 & 1 \\
\hline & 2 & 417/3707 (11.2) & $0.790(0.689-0.907)$ & $0.761(0.660-0.876) \#$ & $0.757(0.656-0.874) \#$ & $0.854(0.728-1.002)$ \\
\hline & 3 & 423/3624 (11.7) & $0.824(0.718-0.945)$ & $0.762(0.661-0.877) \#$ & $0.758(0.657-0.874) \#$ & $0.900(0.767-1.057)$ \\
\hline & 4 & 397/3785 (10.5) & $0.731(0.636-0.840) \#$ & $0.651(0.564-0.752) \#$ & $0.620(0.535-0.717) \#$ & $0.819(0.696-0.964)$ \\
\hline \multirow[t]{4}{*}{ FT3 } & 1 & $317 / 3104(10.2)$ & 1 & 1 & 1 & 1 \\
\hline & 2 & 482/4361 (11.1) & $1.095(0.943-1.272)$ & $1.179(1.011-1.375)$ & $1.154(0.988-1.348)$ & $1.095(0.923-1.299)$ \\
\hline & 3 & 521/3897 (13.4) & 1.357 (1.170-1.574) \# & 1.644 (1.410-1.916) \# & 1.558 (1.334-1.819) \# & 1.515 (1.276-1.798) \# \\
\hline & 4 & 439/3538 (12.4) & $1.245(1.068-1.452)$ & $1.819(1.550-2.134) \#$ & $1.707(1.451-2.008) \#$ & $1.622(1.354-1.942) \#$ \\
\hline \multirow[t]{4}{*}{ FT3FT4 } & 1 & $374 / 3724$ (10.0) & 1 & 1 & 1 & 1 \\
\hline & 2 & 392/3718 (10.5) & 1.056 (0.909-1.226) & $1.227(1.051-1.432)$ & $1.217(1.041-1.423)$ & $1.241(1.045-1.473)$ \\
\hline & 3 & 438/3726 (11.8) & $1.193(1.031-1.381)$ & 1.557 (1.337-1.813) \# & 1.539 (1.319-1.795) \# & $1.423(1.201-1.687) \#$ \\
\hline & 4 & 556/3732 (14.9) & 1.568 (1.364-1.803) \# & $2.372(2.045-2.751) \#$ & 2.329 (2.004-2.705) \# & $1.798(1.522-2.125)$ \# \\
\hline
\end{tabular}

Model 1: crude; model 2: adjusted for age; model 3: adjusted for age, current smoking and alcohol consumption

model 4: adjusted for age, BMI, current smoking and alcohol consumption

$\mathrm{OR}$ and $95 \% \mathrm{Cl}$ for metabolic syndrome were calculated using logistic regression models

Significant associations $(P<0.001)$ are shown in bold 
Table 6 Studies evaluating the relationship between thyroid hormone levels and components of the metabolic syndrome

\begin{tabular}{|c|c|c|c|c|c|c|}
\hline $\begin{array}{l}\text { Author, } \\
\text { year }\end{array}$ & $\mathrm{N}$ & Subjects' age & $\begin{array}{l}\text { Gender } \\
\text { separation? }\end{array}$ & $\begin{array}{l}\text { Corrections for } \\
\text { confounders }\end{array}$ & Major findings & Ref \\
\hline Roos, 2007 & $\begin{array}{l}1581 \\
716 \mathrm{M}\end{array}$ & $28-75$ yrs & No & Age, sex, HOMA-IR & $\begin{array}{l}\text { FT4 negative association with TC, LDL-C, } \\
\text { TG and waist, positive association with } \\
\text { HDL-C, FT3 negative association with TC, } \\
\text { LDL-C, TG }\end{array}$ & [3] \\
\hline Park, 2009 & 949 & $\begin{array}{l}\text { Postmeno- } \\
\text { pausal women }\end{array}$ & Women only & $\begin{array}{l}\text { Age, BMI, HOMA-IR, } \\
\text { FT4, exercise (3 levels), } \\
\text { alcohol (3 levels) }\end{array}$ & $\begin{array}{l}\text { TSH associated with TC, LDL-C, DBP } \\
\text { and TG, MetS }\end{array}$ & [30] \\
\hline Kim, 2009 & $\begin{array}{l}44,196 \\
25,147 \mathrm{M}\end{array}$ & $25-70$ yrs & Yes & Age & $\begin{array}{l}\text { Men: FT4 associated with BP, HDL-C, FBG, } \\
\text { TG, and with WC in those over } 50 \text {; Women: } \\
\text { associated with BP, HDL-C, FBG, WC; no } \\
\text { association with MetS, when adjusted for age }\end{array}$ & [4] \\
\hline $\begin{array}{l}\text { Garduno- } \\
\text { Garcia, } 2010\end{array}$ & 3033 & $18-70$ yrs & No & Age, sex & $\begin{array}{l}\text { TSH associated with TC, TG, WC; FT4 } \\
\text { associated with HDL-C, WC, HOMA-IR; } 10 \% \\
\text { had SCH. }\end{array}$ & [31] \\
\hline Ruhla, 2010 & $\begin{array}{l}1333 \\
481 M\end{array}$ & $>18 \mathrm{yrs}$ & No & Age & $\begin{array}{l}\text { TSH positively associated with BMI, TG, } \\
\text { MetS; no data on FT4 or FT3 }\end{array}$ & [32] \\
\hline Park, 2011 & $\begin{array}{l}5998 \\
3469 \mathrm{M}\end{array}$ & $>18 \mathrm{yrs}$ & No & $\begin{array}{l}\text { Age, sex, BMl, smoking } \\
(y / n) \text {, alcohol }(y / n), \\
\text { exercise }(y / n)\end{array}$ & $\begin{array}{l}\text { TSH and FT4 associated with WC, FBG, } \\
\text { HDL-C, FT4 also with DBP; higher TSH } \\
\text { predicted MetS at follow-up }\end{array}$ & {$[5]$} \\
\hline Tarcin, 2012 & $211,24 \mathrm{M}$ & $\begin{array}{l}\text { Obesity, } \\
18-73 \text { yrs }\end{array}$ & No & Age & $\begin{array}{l}\text { FT3/FT4 negatively associated with FBG, } \\
\text { TG, BP, } \\
\text { TT3 positively with HOMA-IR, FBG, WC }\end{array}$ & [33] \\
\hline $\begin{array}{l}\text { Waring, } \\
2012\end{array}$ & 2119 & $70-79$ yrs & No & $\begin{array}{l}\text { Age, sex, race, BMI, } \\
\text { smoking, HOMA-IR }\end{array}$ & $\begin{array}{l}\text { TSH associated with MetS prevalence, in } \\
\text { entire cohort with broad range of TSH } \\
\text { levels, and in euthyroid range }\end{array}$ & [34] \\
\hline Oh, 2013 & 2760 & $18-39$ & Women only & Age, BMI, HOMA-IR & $\begin{array}{l}\text { TSH between } 2.5 \text { and } 4.5 \text { associated with } \\
\text { BMI, WC, BP, TG }\end{array}$ & [35] \\
\hline Roef, 2014 & $\begin{array}{l}2315 \\
1177 M\end{array}$ & Middle-aged & No & $\begin{array}{l}\text { Age, sex, height, } \\
\text { current smoking }\end{array}$ & $\begin{array}{l}\text { FT3 and FT3/FT4 ratio positively associated } \\
\text { with BMI, WC, TG, BP, FBG, negatively with } \\
\text { HDL-C; FT4 negatively associated } \\
\text { with BMI, WC, TG }\end{array}$ & [36] \\
\hline $\begin{array}{l}\text { Mehran, } \\
2014\end{array}$ & $\begin{array}{l}3755 \\
1709 \mathrm{M}\end{array}$ & $\geq 20 \mathrm{yrs}$ & No & $\begin{array}{l}\text { Age, sex, smoking, } \\
\text { BMI, HOMA-IR }\end{array}$ & $\begin{array}{l}\text { FT4 associated with HDL-C, LDL-C, TG, WC, } \\
\text { BP, but not fasting glucose; no FT3 data }\end{array}$ & [37] \\
\hline $\begin{array}{l}\text { Minami, } \\
2015\end{array}$ & $\begin{array}{l}283 \\
161 M\end{array}$ & $\begin{array}{l}\text { Children, } \\
6-15 \text { yrs }\end{array}$ & Yes & None & $\begin{array}{l}\text { Higher FT3/FT4 ratio in boys with MetS; no } \\
\text { difference thyroid function in girls with MetS }\end{array}$ & [38] \\
\hline $\begin{array}{l}\text { Laclaustra, } \\
2015\end{array}$ & $3533 M$ & $20-65$ yrs & Men only & $\begin{array}{l}\text { Age, alcohol } \\
\text { consumption, smoking } \\
\text { (never, former, current) }\end{array}$ & $\begin{array}{l}\text { Higher TSH \& lowest FT4 quintiles } \\
\text { associated with higher MetS prevalence }\end{array}$ & [39] \\
\hline Kim, 2016 & $\begin{array}{l}13,496 \\
8168 \mathrm{M}\end{array}$ & $\begin{array}{l}\text { Middle-aged, } \\
35-65 \text { yrs }\end{array}$ & No & $\begin{array}{l}\text { Age, sex, \% body fat, } \\
\text { smoking, HOMA-IR }\end{array}$ & $\begin{array}{l}\text { Higher quartiles of } \mathrm{T} 3 \text { and } \mathrm{T} 3 / \mathrm{T} 4 \text { ratio } \\
\text { associated with MetS; only measured } \\
\text { total T4 and T3 levels; modified MetS criteria }\end{array}$ & {$[6]$} \\
\hline Kim, 2017 & $\begin{array}{l}12,037 \\
6950 \mathrm{M}\end{array}$ & $\begin{array}{l}\text { Middle-aged, } \\
35-65 \text { yrs }\end{array}$ & No & Age, sex, smoking & $\begin{array}{l}\text { Highest T3 quartile associated with highest } \\
6 \text {-year MetS incidence; only measured total } \\
\text { T4 and T3 levels; modified MetS criteria }\end{array}$ & [21] \\
\hline $\begin{array}{l}\text { Ferrannini, } \\
2017\end{array}$ & 940 & $30-60$ yrs & No & $\begin{array}{l}\text { Age, sex, BMI, WHR, } \\
\text { family history of diabetes }\end{array}$ & $\begin{array}{l}\text { Higher FT3 associated with decreased } \\
\text { insulin sensitivity (insulin clamp), predicted } \\
\text { follow-up increases in glycaemia }\end{array}$ & [22] \\
\hline Park, 2017 & $\begin{array}{l}132,346 \\
66,991 \mathrm{M}\end{array}$ & $>18 \mathrm{yrs}$ & Yes & $\begin{array}{l}\text { Age, BMl, smoking } \\
\text { status, menopausal } \\
\text { status (in women) }\end{array}$ & $\begin{array}{l}\text { FT3FT4 ratio associated with increased risk } \\
\text { of MetS parameters and insulin resistance }\end{array}$ & [7] \\
\hline
\end{tabular}

$B M I$ body mass index, BP blood pressure, DBP diastolic blood pressure, FBG fasting blood glucose, HDL-C high-density-lipoprotein-cholesterol, $H O M A-I R$ homeostasis-model assessment - insulin resistance, $L D L-C$ low-density-lipoprotein-cholesterol, $M$ males, MetS metabolic syndrome, SCH subclinical hypothyroidism, TC total cholesterol, TG triglycerides, WC waist circumference, WHR waist-to-hip ratio, yrs. years, $y / n$ yes/no

metabolic rate which is induced by the thyroid hormone itself [23]. This author suggested that T3 may stimulate specific neurons that influence appetite-increasing neuropeptides. However, in our data we did observe lower FT4 and higher TSH levels with increasing BMI, but no significant changes of FT3. However, changes in 
brain T3 production may not be mirrored by similar changes in plasma FT3. Another explanation may be that MetS or insulin resistance itself may lead to a relative higher intracellular production of $\mathrm{T} 3$ as a way to compensate -on a local tissue level- for the disturbances in the metabolic state $[24,25]$. The increase in local T3 production may be intended to limit nutrient overload by inducing tissue thermogenesis and simulating metabolic activity $[25,26]$. It has also been postulated that 3,5-diiodo-l-thyronine (T2) has marked effects on energy metabolism in order to protect skeletal muscle against excessive intramyocellular lipid storage [27], that may occur in MetS. A positive energy balance both as a consequence of caloric excess and due to insufficient physical activity may contribute to this. In contrast, caloric restriction and prolonged fasting have been associated with lower type 2 deiodinase activity, which will reduce the conversion of $\mathrm{T} 4$ to $\mathrm{T} 3$ and lower plasma (F)T3 levels, and an increase in the conversion to reverse T3. In addition, the slightly lower (F)T4 levels observed in obesity themselves may upregulate tissue type 2 deiodinase activity, thereby leading to a relative increase of $\mathrm{T} 3$. Other factors which may influence tissue deiodinase activity and thereby resulting T3 levels are changes in circadian rhythm. Indeed, it has been shown that disturbances in sleep pattern may play a role in the development of obesity and diabetes [28, 29].

Our study has several strengths, but also some weaknesses. It comprises a large dataset of participants from the general population with available thyroid hormone parameters. Also, all subjects have been uniformly characterized, with well-standardized BP measurements and blood drawing in the fasting state, thereby minimizing the effect of possible circadian changes in thyroid hormone parameters. The large number of participants allowed to assess all relationships for men and women separately, which is of importance considering the significant differences between sexes for a large number of baseline characteristics (Table 1). As mentioned, this is one of the few studies in which confounding factors like smoking and alcohol have been taken into account. Currently, we lack information regarding menopausal status of the female participants, which may influence the possible difference between sexes. Also, data on physical activity could not be taken into account, and it is known that this factor may directly influence some MetS components, and is an important factor in maintaining an optimal energy balance. Tests to measure anti-thyroid peroxidase antibody levels were not available. Due to the cross-sectional design, we can not evaluate the effects of thyroid hormone parameters on future development of MetS. This also relates to the fact that the LifeLines study did not systematically collect medication use during follow-up investigations.

\section{Conclusions}

In conclusion, plasma levels of both FT4 and FT3 are associated with several components of the MetS, after correction for possible important confounding factors. In the highest FT3 and FT3FT4 quartiles there is a $50-80 \%$ increased risk of having MetS compared to the lowest quartile. Further studies are needed to assess the possible causality of this relationship.

\section{Additional files}

\section{Additional file 1: Table S1. Thyroid hormone parameters and components of the metabolic syndrome - men. Thyroid hormone parameters and components of the metabolic syndrome for TSH, FT4, TF3 and FT3FT4 quartiles, respectively, separately for men only. (DOCX 11 kb)}

Additional file 2: Table S2. Thyroid hormone parameters and components of the metabolic syndrome - women. Thyroid hormone parameters and components of the metabolic syndrome for TSH, FT4, TF3 and FT3FT4 quartiles, respectively, separately for women only. (DOCX $11 \mathrm{~kb}$ )

\section{Abbreviations}

BMI: Body mass index; BP: Blood pressure; FBG: Fasting blood glucose; HbA1c: Glycated haemoglobin; HDL-C: High-density lipoprotein cholesterol; LDL-C: Low density lipoprotein cholesterol; MetS: Metabolic syndrome; OR: Odds ratio; TC: Total cholesterol; TG: Triglycerides; WC: Waist circumference

\section{Acknowledgements}

The authors wish to acknowledge all participants of the LifeLines Cohort Study and everybody involved in the set-up and implementation of the study.

\section{Funding}

Lifelines has been funded by a number of public sources, notably the Dutch Government, The Netherlands Organization of Scientific Research NOW [grant 175.010.2007.006], the Northern Netherlands Collaboration of Provinces (SNN), the European fund for regional development, Dutch Ministry of Economie Affairs, Pieken in de Delta, Provinces of Groningen and Drenthe, the Target project, BBMRI-NL, the University of Groningen, and the University Medical Center Groningen, The Netherlands. This work was supported by the National Consortium for Healthy Ageing, and funds from the European Union's Seventh Framework program (FP7/2007-2013) through the BioSHaRE-EU (Biobank Standardisation and Harmonisation for Research Excellence in the European Union) project, grant agreement 261,433. LifeLines (BRIF4568) is engaged in a Bioresource research impact factor (BRIF) policy pilot study, details of which can be found at: http://www.bioshare.eu/ content/bioresource-impact-factor

\section{Availability of data and materials}

The manuscript is based on data from the LifeLines Cohort Study. The data that support the findings of this study are available from LifeLines but restrictions apply to the availability of these data, which were used under license for the current study, and so are not publicly available. The LifeLines system allows access upon request for reproducibility of the study results. The data catalogue of LifeLines is publicly accessible on https:// www.lifelines.nl/researcher. All international researchers can apply for data at the LifeLines research office (LLscience@umcg.nl).

\section{Authors' contributions}

BHRW was the primary investigator. SNS, MMvdK and BHRW contributed to the study design. SNS and BHRW performed the statistical analyses. HJCMW, SNS, RPVW, ACMK, JVVVO, TPL, MMvdK contributed to interpretation of the data and analyses. BHRW drafted the manuscript. All authors read and approved the final manuscript. 


\section{Ethics approval and consent to participate}

The study protocol was approved by the medical ethical review committee of the University Medical Center Groningen. All participants provided written informed consent before participating in the study.

\section{Consent for publication}

Not applicable.

\section{Competing interests}

The authors declare that they have no competing interests.

\section{Publisher's Note}

Springer Nature remains neutral with regard to jurisdictional claims in published maps and institutional affiliations.

\section{Author details}

'Department of Endocrinology, University of Groningen, University Medical Center Groningen, HPC AA31, P.O. Box 30001, 9700 RB Groningen, The Netherlands. ${ }^{2}$ Department of Clinical Chemistry, University of Groningen, University Medical Center Groningen, HPC AA31, P.O. Box 30001, 9700 RB Groningen, The Netherlands.

\section{Received: 21 June 2017 Accepted: 9 October 2017}

Published online: 16 October 2017

\section{References}

1. Alberti KG, Eckel RH, Grundy SM, Zimmet PZ, Cleeman Jl, Donato KA, et al. Harmonizing the metabolic syndrome: a joint interim statement of the international diabetes federation task force on epidemiology and prevention; National Heart, Lung, and Blood Institute; American Heart Association; world heart federation; international atherosclerosis society; and International Association for the Study of obesity. Circulation. 2009;120: 1640-5.

2. Cornier MA, Dabelea D, Hernandez TL, Lindstrom RC, Steig AJ, Stob NR, et al. The metabolic syndrome. Endocr Rev. 2008;29:777-822.

3. Roos A, Bakker SJ, Links TP, Gans RO, Wolffenbuttel BH. Thyroid function is associated with components of the metabolic syndrome in euthyroid subjects. J Clin Endocrinol Metab. 2007;92:491-6.

4. Kim BJ, Kim TY, Koh JM, Kim HK, Park JY, Lee KU, et al. Relationship between serum free T4 (FT4) levels and metabolic syndrome (MS) and its components in healthy euthyroid subjects. Clin Endocrinol. 2009:70:152-60.

5. Park SB, Choi HC, Joo NS. The relation of thyroid function to components of the metabolic syndrome in Korean men and women. J Korean Med Sci. 2011;26:540-5

6. Kim HJ, Bae JC, Park HK, Byun DW, Suh K, Yoo MH, et al. Triiodothyronine levels are independently associated with metabolic syndrome in Euthyroid middle-aged subjects. Endocrinol Metab (Seoul). 2016;31:311-9.

7. Park SY, Park SE, Jung SW, Jin HS, Park IB, Ahn SV, et al. Free triiodothyronine/free thyroxine ratio rather than thyrotropin is more associated with metabolic parameters in healthy euthyroid adult subjects. Clin Endocrinol. 2017:87:87-96.

8. Slagter SN, van Vliet-Ostaptchouk JV, Vonk JM, Boezen HM, Dullaart RP, Kobold AC, et al. Combined effects of smoking and alcohol on metabolic syndrome: the LifeLines cohort study. PLoS One. 2014;9:e96406.

9. Stolk RP, Rosmalen JG, Postma DS, de Boer RA, Navis G, Slaets JP, et al. Universal risk factors for multifactorial diseases: LifeLines: a three-generation population-based study. Eur J Epidemiol. 2008;23:67-74.

10. Scholtens S, Smidt N, Swertz MA, Bakker SJ, Dotinga A, Vonk JM, et al. Cohort profile: LifeLines, a three-generation cohort study and biobank. Int J Epidemiol. 2015;44:1172-80.

11. Schubert CC, Boustani M, Callahan CM, Perkins AJ, Carney CP, Fox C, et al. Comorbidity profile of dementia patients in primary care: are they sicker? $\mathrm{J}$ Am Geriatr Soc. 2006;54:104-9.

12. Klaver El, van Loon HC, Stienstra R, Links TP, Keers JC, Kema IP, et al. Thyroid hormone status and health-related quality of life in the LifeLines cohort study. Thyroid. 2013;23:1066-73.

13. American Diabetes A. Diagnosis and classification of diabetes mellitus Diabetes Care. 2010:33(Suppl 1):S62-9.

14. Lee K. Gender-specific relationships between alcohol drinking patterns and metabolic syndrome: the Korea National Health and nutrition examination survey 2008. Public Health Nutr. 2012;15:1917-24.
15. Marchi KC, Muniz JJ, Tirapelli CR. Hypertension and chronic ethanol consumption: what do we know after a century of study? World J Cardiol. 2014;6:283-94

16. Grundy SM. Metabolic syndrome pandemic. Arterioscler Thromb Vasc Biol. 2008;28:629-36

17. Lee YJ, Woo SY, Ahn JH, Cho S, Kim SR. Health-related quality of life in adults with metabolic syndrome: the Korea national health and nutrition examination survey, 2007-2008. Ann Nutr Metab. 2012;61:275-80.

18. van Vliet-Ostaptchouk JV, Nuotio ML, Slagter SN, Doiron D, Fischer K, Foco $L$, et al. The prevalence of metabolic syndrome and metabolically healthy obesity in Europe: a collaborative analysis of ten large cohort studies. BMC Endocr Disord. 2014;14:9.

19. Slagter SN, van Vliet-Ostaptchouk JV, van Beek AP, Keers JC, Lutgers HL, van der Klauw MM, et al. Health-related quality of life in relation to obesity grade, type 2 diabetes, metabolic syndrome and inflammation. PloS one 2015;10:e0140599.

20. Slagter $S N$, van Waateringe RP, van Beek AP, van der Klauw MM, Wolffenbuttel BHR, van Vliet-Ostaptchouk JV. Sex, BMI and age differences in metabolic syndrome: the Dutch Lifelines cohort study. Endocr Connect. 2017:6:278-88

21. Kim HJ, Bae JC, Park HK, Byun DW, Suh K, Yoo MH, et al. Association of triiodothyronine levels with future development of metabolic syndrome in euthyroid middle-aged subjects: a 6-year retrospective longitudinal study. Eur J Endocrinol. 2017:176:441-50.

22. Ferrannini E, lervasi G, Cobb J, Ndreu R, Nannipieri M. Insulin resistance and normal thyroid hormone levels: prospective study and metabolomic analysis. Am J Physiol Endocrinol Metab. 2017;312:E429-E36.

23. Oliveira RM. Role of type 2 deiodinase in hypothalamic control of feeding behavior. J Endocrinology, Diabetes \& Obesity. 2014;2:1048

24. Bianco AC, Silva JE. Intracellular conversion of thyroxine to triiodothyronine is required for the optimal thermogenic function of brown adipose tissue. $J$ Clin Invest. 1987:79:295-300.

25. Silva JE. The thermogenic effect of thyroid hormone and its clinical implications. Ann Intern Med. 2003;139:205-13.

26. Silvestri E, Schiavo L, Lombardi A, Goglia F. Thyroid hormones as molecular determinants of thermogenesis. Acta Physiol Scand. 2005;184:265-83.

27. Lombardi A, de Lange P, Silvestri E, Busiello RA, Lanni A, Goglia F, et al 3,5-Diiodo-L-thyronine rapidly enhances mitochondrial fatty acid oxidation rate and thermogenesis in rat skeletal muscle: AMP-activated protein kinase involvement. Am J Physiol Endocrinol Metab. 2009;296: E497-502.

28. St-Onge MP, Grandner MA, Brown D, Conroy MB, Jean-Louis G, Coons M, et al. Sleep duration and quality: impact on lifestyle behaviors and cardiometabolic health: a scientific statement from the American Heart Association. Circulation. 2016:134:e367-e86.

29. Dutil C, Chaput JP. Inadequate sleep as a contributor to type 2 diabetes in children and adolescents. Nutr Diabetes. 2017:7:e266

30. Park HT, Cho GJ, Ahn KH, Shin JH, Hong SC, Kim T, et al. Thyroid stimulating hormone is associated with metabolic syndrome in euthyroid postmenopausal women. Maturitas. 2009;62:301-5.

31. Garduno-Garcia Jde J, Alvirde-Garcia U, Lopez-Carrasco G, Padilla Mendoza ME, Mehta R, Arellano-Campos O, et al. TSH and free thyroxine concentrations are associated with differing metabolic markers in euthyroid subjects. Eur J Endocrinol. 2010;163:273-8.

32. Ruhla S, Weickert MO, Arafat AM, Osterhoff M, Isken F, Spranger J, et al. A high normal TSH is associated with the metabolic syndrome. Clin Endocrinol. 2010; 72:696-701.

33. Tarcin O, Abanonu GB, Yazici D, Tarcin O. Association of metabolic syndrome parameters with $\Pi 33$ and FT3/FT4 ratio in obese Turkish population. Metab Syndr Relat Disord. 2012;10:137-42.

34. Waring AC, Rodondi N, Harrison S, Kanaya AM, Simonsick EM, Miljkovic I, et al. Thyroid function and prevalent and incident metabolic syndrome in older adults: the health, ageing and body composition study. Clin Endocrinol. 2012; 76:911-8

35. Oh JY, Sung YA, Lee HJ. Elevated thyroid stimulating hormone levels are associated with metabolic syndrome in euthyroid young women. Korean J Intern Med. 2013;28:180-6

36. Roef $\mathrm{GL}$, Rietzschel ER, Van Daele CM, Taes YE, De Buyzere ML, Gillebert TC, et al. Triiodothyronine and free thyroxine levels are differentially associated with metabolic profile and adiposity-related cardiovascular risk markers in euthyroid middle-aged subjects. Thyroid. 2014;24:223-31. 
37. Mehran L, Amouzegar A, Tohidi M, Moayedi M, Azizi F. Serum free thyroxine concentration is associated with metabolic syndrome in euthyroid subjects. Thyroid. 2014;24:1566-74.

38. Minami Y, Takaya R, Takitani K, Ishiro M, Okasora K, Niegawa T, et al. Association of thyroid hormones with obesity and metabolic syndrome in Japanese children. J Clin Biochem Nutr. 2015;57:121-8.

39. Laclaustra M, Hurtado-Roca Y, Sendin M, Leon M, Ledesma M, Andres E, et al. Lower-normal TSH is associated with better metabolic risk factors: a cross-sectional study on Spanish men. Nutr Metab Cardiovasc Dis. 2015;25: 1095-103.

Submit your next manuscript to BioMed Central and we will help you at every step:

- We accept pre-submission inquiries

- Our selector tool helps you to find the most relevant journal

- We provide round the clock customer support

- Convenient online submission

- Thorough peer review

- Inclusion in PubMed and all major indexing services

- Maximum visibility for your research

Submit your manuscript at www.biomedcentral.com/submit 